\title{
Curriculum Adaptation and the Accommodation of Children with Dyslexia in Regular Schools in Buea Sub-Division, Cameroon
}

\author{
Patrick Fonyuy Shey, PhD \\ Department of Educational Psychology \\ University of Buea, Cameroon
}

\begin{abstract}
Dyslexia is a term that describes why given populations of school-going children fail to acquire reading skills in spite of normal intelligence, adequate environmental and educational opportunities. The main objective of this study was to find out the effect of curriculum adaptation on the accommodation of learners with dyslexia in regular schools in Buea Sub-Division. The study was anchored on the Dual Route theory theory. A purposive sampling technique was done with six schools and 65 teachers selected for the study. A semistructured questionnaire with 24 close ended items and 5 open ended items was used to collect data. Data were made essentially of categorical variables and they were analyzed using frequency, proportions and Multiple Response Analysis to aggregate responses within conceptual components. The findings revealed that teachers faced a lot of difficulties in teaching children with dyslexia in regular classrooms with $87.7 \%$ (57) of the teachers admitted that they teach strictly on prescribed scheme of work. There was enough statistical evidence that material quantity taught per day significantly and positively influenced the effectiveness of learners with dyslexia, $64.6 \%$ (42) admitted that children are more careful when they have limited task under limited time, the better the management of classrooms by teachers, the better the content delivery for learners with dyslexia. The study recommends issues to be addressed in order to enhance the implementation of the adapted curriculum in regular schools amongst which were; the revision of school curriculum by The Ministry of Basic Education in order to make it flexible so that teachers have room to use different teaching styles to achieve the same objectives, curriculum designers and special educators should be jointly responsible for training teachers on curriculum adaptation.
\end{abstract}

Keywords: Curriculum Adaptation, Accommodation and Dyslexia.

\section{INTRODUCTION}

The Education for All movement that involved various international organizations such as UNESCO, UNICEF and the World Bank was launched in 1990 at the World Conference in Jomtien, Thailand. The main item on the agenda of this conference was Education for All in the entire world. In Cameroon however, more than two decades after this conference, the concept of education for all is not implemented: there are neither policies nor a legal framework that advocates education for all. The United Nations Economic Scientific and Cultural organization, UNESCO (1990), emphasizes that all children have a right to be educated together despite their physical, intellectual, social, linguistic or other conditions. Literacy skills and in particular reading are essential for success in education as reading skills are utilized in all academic subjects. While some children read with ease, there are those learners with developmental reading difficulties or dyslexia, to whom reading is an extremely daunting task. To accommodate these children in a regular school, there is need for curriculum adaptation.

\section{BACKGROUND KNOWLEDGE ON DYSLEXIA}

Dyslexia, a difficulty in learning to read was first described in scientific literature by several physicians, who noted cases of individuals with apparently normal intelligence who could not learn to read. These cases were called word blindness. One of the pioneers in the field of dyslexia was Orton (1925), who believed that the problem in dyslexia was one of visual perception and visual memory. In the years that followed, various theories, including hypotheses about motor difficulties and perceptual problems as the basis of dyslexia, were advanced. The belief was that dyslexia was a perceptual problem, stemming from the idea of word blindness. It was also a common belief, and probably a belief held by many today, that the defining symptom for dyslexia was writing letters and words 
backwards. This conceptualization of dyslexia as a visual problem with the primary symptom being the writing of letters and words backwards has been discredited by studies, including those by Liberman, Shankweiler, Orlando, Harris, Berti (1971). A breakthrough in the understanding of dyslexia occurred approximately 35 years ago, when a picture of the major cognitive difficulties in dyslexia began to emerge more clearly.

Lieberman (1985), recognized the importance of speech and language as the basis for reading, and that children must map the written word on to the spoken word when learning to read. It hitherto had been assumed that visual difficulties or problems with hand-eye coordination served as the basis for dyslexia. It is now clear that the major problem with dyslexia involves difficulties with phonological processing, that is, being able to segment words into their component sounds, and associate letters with their sounds and phonological awareness (that is, the ability to segment speech into small parts, such as syllables, and the smallest units of sound, phonemes). Dyslexia is a neurobiological disorder that affects $80 \%$ of all learners with learning difficulties in varying degrees. It is a disorder that cuts across all socio-economic classes and exists in all cultures though the prevalence may vary from one language to another depending on how transparent the language is and ranges from a low to high prevalence. It is identified in childhood and persists through adolescence to adulthood. Failure to identify the disorder early enough and provide early intervention, leads to learners struggling with poor academic performance coupled with low self-esteem, emotional trauma and increased chances of school dropout.

As young children, dyslexics have difficulties with tasks such as discriminating the individual sounds in words (for example, what does 'pink' without the 'p' say?), recognizing words that rhyme (example, which of the following words rhymes with cat: sun, hat or star) or recognizing whether 'cat' and 'kite' start with the same sound. Studies such as those by Elbro and Pellesen (2002), have shown that children who receive training in these phonological awareness skills demonstrate improved reading abilities. When dyslexics are learning to read, they have trouble learning the sounds of letters and the spelling of words. Later on, although they can read words, their reading may be slow, and many have difficulty remembering what they have read. Stanovich (1990), provided evidence for what he called the 'Matthew effect' (based on the writings of Matthew in the Bible that the rich get richer and the poor get poorer). Stanovich (1990), states that "individuals who have advantageous early educational experiences are able to utilize new educational experiences more efficiently". In contrast, children who have reading difficulties read less and do not acquire the vocabulary and concepts that they need and, thus, fall further behind in their reading and academic skills.

The current consensus based on a large body of research (such as Irby, Brown, Alecio, \& Jackson 2013; Johnsen \& Skjorten; 2001), is that dyslexia is best characterized as a problem with language processing at the phoneme level, not a problem with visual processing. Studies have also shown that Dyslexics tend to be above average to genius level in intelligence. It is not uncommon for gifted children to have dyslexic issues. Often this can make it difficult to identify them and they can be regarded as "lazy and not living up to their potential" but the concept of universal design proves differently.

Around the 1900s the concept of Universal Design originated in the field of architecture as a response to concerns about the inefficiency of individualized retrofitted solutions in buildings, and the inappropriateness of placing the burden of adaptation on individuals. Architect Ron Mace coined the term Universal Design in the early 1980s, and defined the concept as "the design of products and environments to be usable by all people, to the greatest extent possible, without the need for adaptation or specialized design" (Centre for Universal Design, 1997). Mace, a wheelchair user, had personal experience with the failings of traditional design and was a pioneering advocate of aesthetically pleasing and usable design to meet the needs of people, regardless of their age or ability (Centre for Universal Design, 1998).

Architects practicing Universal Design created structures that were intended from the outset to be used by all individuals, including those with disabilities. "The intent of Universal Design was to simplify life for everyone by making products, communications, and the built environment more usable by as many people as possible at little or no extra cost" (Centre for Universal Design, 1997). Universally accessible features such as ramped entrances and automatic doors are now routinely included in new construction intended for public use, such as government buildings, shopping malls, 
and schools. In addition to physical structures, the concept of Universal Design had been extended to other products and to the field of communications. For example, when television captioning was first made available, it was only available to those who purchased expensive decoder boxes. Later, decoder chips were built into all televisions, making captions universally available. Research shows that the captioning feature has proved to be of benefit to many users who do not have hearing impairments, including patrons of noisy restaurants, exercisers in health clubs, individuals seeking to improve their English language skills (dyslexics) and couples going to sleep at different times.

Reid (2009), with the concept of Universal Design in his article Dyslexia commented on the practice and principles of selecting appropriate teaching approaches for use with children with dyslexia. $\mathrm{He}$ divided Teaching approaches into four broad areas: individualized approaches; support approaches; assisted learning and whole-school approaches. Reid (2009) further stated that, determining the most appropriate programmes and strategies for children with dyslexia, a number of factors must be considered, the most important of which are the following:

- The context (the nature of the learning and teaching provision and the age and stage of the individual);

- the assessment (in what way does the assessment inform teaching, can the individual's strengths and difficulties be readily identified from the results of the assessment);

- the curriculum (how can the teaching programme be related to the curriculum -are any gains made by the programme readily transferable to other aspects of the curriculum);

- The learner (what are the individual factors which can help the learner make appropriate gains from the programme-is the programme suitable for the individual's learning style?).

He proposed therefore that it was important to view teaching programmes in relation to the individual and not in relation to the syndrome -'dyslexia'.

However, some programmes may have been highly evaluated by practitioners and have had an established reputation as a successful multi-sensory programme, but this does not necessarily mean that the programme will be effective with all dyslexic children. Each child has to be viewed individually. Adapting the curriculum will create a place for these children with dyslexia to be accommodated. Adaptations occur when teachers differentiate instruction, assessment and materials in order to create a flexible learning environment. For example, a student could be working on below grade level learning outcomes in Language Arts and at grade level in all other subjects or courses, some of which require reading materials at the lower reading level.

\section{The Problem}

The changing climate of our classrooms today increasingly includes populations of learners with dyslexia. In a climate of standards/objectives based reform, educators have to seek ways to address diversity in classrooms and employ practices that meet the needs of all learners. As a result, many public schools adopt curricula aligned to national standards under the auspice of making planning easier for teachers or preparing learners for end of term or end of course examinations. Often times, classroom teachers may not be included or have limited input in the process of adapting curriculum. The case in Cameroon is that, curriculum issues are determined by central administrators in the Ministry of Basic Education. When teachers are not included in the curriculum adaption process or curriculum decision-making, they are forced to plan and deliver curriculum that may neither be appropriate for meeting the needs of their diverse learners nor permit opportunities for individualized instruction.

Still in Cameroon, one finds a disconnection between the needs of children with dyslexia and the system of instructional delivery, including curriculum, planning, and materials in Regular schools. The curriculum materials should be chosen based on evidence that they contribute to the production of meaningful learning experiences. Educators, in Cameroon, are attempting to close the achievement gap as judged against proficiency delineated by standards in academic areas, without being equipped with the proper tools to meet the learning needs of children with dyslexia. In an era of educational reform, appropriate curricula and materials are essential for embracing the background knowledge of diverse learners. Teachers' voices and involvement are essential for developing and adapting curricula 
and adjusting learning experiences and formative assessments to create educational success. Appropriate curricula allow teachers to create lessons that empower learners to be successful. When teachers are not given the autonomy to create appropriate curricula, the planned curricula, especially when scripted, is informally modified through instructional delivery. With the national curriculum, children with dyslexia are left behind, some end up with literacy difficulties, low self-esteem and the development of emotional and behavioural difficulties. It is against this background that a study was proposed on the effect of curriculum adaptation on the accommodation of children with dyslexia in selected regular schools in Buea Sub -Division.

\section{Main Research Question}

Does curriculum adaptation have any effect on the accommodation of children with dyslexia in regular schools?

\section{Specific Research Questions}

- Does the adjustment in material quantity taught per day affect the effectiveness of learners with dyslexia?

- How does adjustment in classroom management affect the delivery content for learners with dyslexia?

\section{LITERATURE}

\subsection{The Concept of Dyslexia, Adaptation and Accommodation}

There is no recipe for adapting general education curriculum to meet each student's needs. Each teacher, each student, each classroom is unique and adaptations are specific to each situation. Differentiating instruction and providing multiple ways to assessment allows more flexibility for learners to meet the standards and requirements of the class. Differentiating instruction which is a form of curriculum adaptation can facilitate accommodations. In addition, supports for one student may not necessarily be the same in all situations. This brief conceptual review provides information about curriculum adaptations that could be considered in developing the appropriate strategy for the accommodation of learners with dyslexia

\subsection{Dyslexia}

Dyslexia is a language-based learning disability that affects reading and writing. It is referred to as a learning disability because dyslexia can make it very difficult for a learner to succeed academically in the typical instructional environment. Dyslexia cannot be cured but managed. It is a neurobiological disorder that is present in all cultures, cuts across all socio-economic backgrounds and is present in children of low, average and superior intelligence. The World Health Organization, International Classification of Disability (2010) defines dyslexia as a disorder manifested by difficulty learning to read despite conventional instruction, adequate intelligence and socio-cultural opportunity whereas the American Psychiatry Association (APA) DSM IV-TR defines it as the reading achievement that is substantially below that expected given the person's chronological age, measured intelligence and age-appropriate education. The APA, DSM IV-TR categorizes reading disorder/ dyslexia as a disorder first diagnosed in infancy, childhood or adolescence (American Psychiatric Association, 2000). The DSM 5 has dyslexia under the category of specific Learning Disorders (SLD) and defines SLD as "persistent difficulties in learning and using academic skills as indicated by either inaccurate or slow and effortful word reading or by difficulties with spelling or both". "It is a disorder that is characterized by an expected difficulty in reading in children and adults".

There is a general consensus that children with dyslexia have difficulties at the phonological level (Fawcett \& Nicolson, 2004) and thus have difficulties identifying letters sounds, mapping the letter names to their letter sounds and breaking a word into its constituent sound. Thus a child with dyslexia may substitute, replace, omit or add some letter sounds during a reading discourse or spelling task. Some children will have difficulties blending sounds to make words, while some will have difficulties with word storage and retrieval. A dyslexic reader will stumble, guess or sound out words while reading, their reading speed or fluency is much slower than non-impaired readers of their age and thus their reading is always a laborious task. 


\subsection{The Concept of Curriculum Adaptation}

Donald, Lazarus and Lolwana (2002) define the curriculum as being more than just the syllabus. Apart from the content, the curriculum also includes the goals and processes of promoting the holistic development of the learner and the structure of the programme. UNESCO (2004) supports the idea of Donald et al. (2002) by adding that the curriculum is what is learned and what is taught (context); how it is delivered (teaching - learning methods); how it is assessed (examination, for example) and the resources used (example; books used to deliver and support teaching and learning). Curriculum Adaptations are changes which are permissible in educational environment allowing the student equal opportunity to obtain access, results, benefits and level of achievement.

Therefore, curriculum adaptations involve making changes by eliminating or adapting parts of the curriculum as well as the teaching and learning environment, which enables learners to learn from the curriculum designed for their age group in an inclusive education setting.

\subsection{Accommodation}

Accommodations being as a result of adaptation are the actual supports that provide students with equal access to instruction. There are four major categories of accommodations, these are: (1) Presentation of the instruction material (example, orally present classroom material); (2) Student response to classroom instruction (example, use of word processor); (3) Instruction timing (example, extended time on activities); and (4) Instructional setting (example, resource room). When these changes are made, accommodation (placing of learners with educational needs together in a regular classroom) now becomes a reality.

\subsection{Theoretical Reflections}

To further comprehend the subject matter under study, the application of Dual-route Theory provided a powerful theoretical framework for interpreting the written language performance of individuals with acquired alexia/agraphia specifying the functional architecture of the written language processing system.

\subsection{The "Dual Route" Model for Reading}

Dual-route models are scientific hypotheses about the cognitive architecture of the informationprocessing system used for reading and spelling (Coltheart, Rastle, Perry, Langdon, \& Ziegler, 2001). According to these models, written language processing is accomplished by two distinct but interactive procedures that are referred to as the lexical and non-lexical routes. Reading and spelling by the lexical route relies on the activation of word-specific orthographic and phonological memory representations. Although spoken and written words also automatically activate the corresponding conceptual representations in the semantic system, access to word meanings is not considered critical for accurate oral reading or spelling to dictation. The lexical route can process all familiar words, regardless of whether they are regular or irregular in terms of their letter-sound relationships, but it fails with unfamiliar words or non-words because these items do not have lexical representations. In contrast to the whole-word retrieval process employed by the lexical route, the non-lexical route utilizes a sub word-level procedure based on sound-spelling correspondence rules.

It should be noted that although dual-route models contain functional components that are unique to lexical route (example, orthographic lexicon) or the non-lexical route (example, phoneme-grapheme conversion module), the two procedures are not considered to be completely independent. For instance, the two routes share processing components at the phoneme and letter levels. Furthermore, it is assumed that all written and spoken input is processed obligatorily by both routes in parallel, with cooperative or competitive interactions taking place at the phoneme (reading) or letter (spelling) output stage (Coltheart et al., 2001). However, dual-route theory maintains that only the lexical route can deliver a correct response to irregular words, whereas the integrity of the non-lexical route is essential for accurate reading/spelling of non-words.

Dual-route models have provided a powerful theoretical framework for interpreting the written language performance of individuals with acquired alexia/agraphia. In particular, by specifying the functional architecture of the written language processing system it becomes possible to use the impaired and preserved reading/spelling abilities of neurological patients to identify the damaged or dysfunctional cognitive module. For instance, damage to the lexical route gives rise to surface 
dyslexia/dysgraphia, characterized by a disproportionate difficulty in reading/spelling irregular words. Reading/spelling of regular words and non-words is relatively spared, however, as these items can be processed successfully by the intact non-lexical route. By contrast, damage to the non-lexical route results in phonological dyslexia / dysgraphia, characterized by poor reading/spelling of non-words. Reading / spelling of familiar regular and irregular words is relatively unimpaired because, for these items, learner can rely on the preserved lexical route.

Linking the dual-route model of single word reading with the E-Z Reader model of eye movement control during silent sentence reading, a dysfunction of the lexical route was assumed to account for a reduced number of words which received only a single fixation or which were skipped and for the increased number of words with multiple fixations and a marked effect of word length on gaze duration. This pattern was interpreted as a frequent failure of orthographic whole-word recognition (based on orthographic lexicon entries) and on reliance on serial sub-lexical processing instead. Inefficiency of the lexical route was inferred from prolonged gaze durations for singly fixated words. These findings were related to the E-Z Reader model of eye movement control. Slow activation of word phonology accounted for the low skipping rate of dyslexic readers. Frequent reliance on sub lexical decoding was inferred from a tendency to fixate word beginnings and from short forward saccades. Overall, the linkage of the dual-route model of single word reading and a model of eye movement control led to a useful framework for understanding eye movement abnormalities of dyslexic readers.

The lexical route leads to phonology via orthographic whole-word recognition units which get instantiated by familiar letter strings and provide direct access to whole-word phonology and meaning. The sub lexical route of the dual-route model leads to word phonology via serial conversion of graphemes into phonemes. In an orthographic lexical decision task (that is, Is xxx correctly written?), Bergmann and Wimmer (2008) found that dyslexic readers exhibited major difficulty with the orthographic distinction between words and pseudo-homophones (example., Taxi and Taksi), indicating that their orthographic word lexicon contained fewer fully specified orthographic word recognition units. However, even when such recognition units were available and used, the speed of access to word phonology was markedly impaired. This was evident from the latencies in the subsequent phonological lexical decision task. Moreover, the sub lexical route was found to be even more speed impaired than the lexical route.

\subsection{Studies Related to Adaptations and Accommodation of Learners with Dyslexia}

Mzizi (2014) conducted a study on Curriculum Adaptations for Learners with learning impairments In the Foundation Phase in Thabo Mofutsanyana Education District, Free State Province. In this study, Mzizi focused on the level of knowledge and skills of foundation phase teachers on curriculum adaptations for learners with learning impairments. The sample consisted of 20 foundation phase teachers and 22 learners. Interviews were conducted with 20 teachers and the researcher observed the interaction between teachers and learners as well as the interaction between the learners themselves. Field notes were also taken during fieldwork. The findings indicated that most teachers understood what the adaptations were; although only few aspects of the curriculum were understood to be adapted to the needs of learners with learning impairments. Some teachers gave learners varying activities whilst other teachers gave all their learners the same activities. The teachers mentioned that they gave different activities to individual learners during expanded opportunity time, which was, according to the researcher, time consuming.

The study recommends that the Learning Support Advisors (LSAs) and Subject Advisors (SAs) should conduct in-services training in which foundation phase teachers are trained in curriculum adaptations. Teachers should be asked how they explore the meaning of curriculum adaptations. This strategy will help the facilitators to identify what teachers already know, and build on that knowledge. The question and answer technique will serve as an introduction to the training. The LSAs and the SAs should conduct the training using different teaching strategies. Thereafter, they should highlight strategies such as: Multilevel instruction; cognitive training which entails self - instruction, self monitoring, scaffold instruction and reciprocal teaching; content enhancement which entails graphic organizers; mnemonics and peer assisted learning strategy; direct instruction, peer tutoring and cooperative learning. 
In the article Effective Classroom Management, Mansor, Eng, Rasul, Hamzah, and Hamid (2012) talk about learning outcomes being directly related to the learning environment within the classroom created by the teacher. A qualitative research study done by Richardson and Fallon (2001) found that classroom management is interconnected with the goals and beliefs of the teacher and with their manner. Manner referred to the teachers' character traits as revealed within a classroom and is believed to be important for student learning (Richardson \& Fallon, 2001).Thus, classroom management encompasses the overall learning environment where students are able to foster their learning.

\section{Methodology}

\subsection{Research Design}

The research design chosen for the study was a descriptive survey as it sought to assess the effects of curriculum adaptation on the accommodation of children with dyslexia in regular schools. A questionnaire with close-ended items was used as the main data collection tool. Notably, the closeended items were analyzed using the quantitative approach whereby responses were weighted as to appreciate the trend and rank for statistical comparison.

The population of the study was made up of 221 nursery and primary schools with 1330 teachers (184 males and 1145 females).

Table1. Distribution of nursery and primary school teachers in Buea Sub-division

\begin{tabular}{|l|l|l|l|}
\hline School type & Male & Female & Total \\
\hline Government primary schools & 23 & 243 & 266 \\
\hline Government nursery schools & 00 & 90 & 90 \\
\hline Catholic primary schools & 14 & 75 & 89 \\
\hline Catholic nursery school & 01 & 15 & 16 \\
\hline Presbyterian primary school & 03 & 28 & 31 \\
\hline Presbyterian nursery school & 00 & 06 & 06 \\
\hline Baptist primary school & 05 & 26 & 31 \\
\hline Baptist nursery school & 00 & 08 & 08 \\
\hline Islamic primary school & 03 & 03 & 06 \\
\hline Islamic nursery school & 02 & 01 & 03 \\
\hline Private primary school & 125 & 426 & 551 \\
\hline Private nursery school & 08 & 225 & 233 \\
\hline Total:221 schools & 184 & 1146 & 1330 \\
\hline
\end{tabular}

Source: Inspectorate of Basic Education for Fako-Division, South West Region

Among the 221 primary and nursery schools in Fako Division of the South West Region of Cameroon, 6 were purposively sampled and 65 teachers were involved in the study. The schools were Potters House Education Centre Bokwai, Menanjomo Special Education Centre Molyko, Government School Molyko, Government Nursery School Bokwai, Shallom Bilingual School Bokova and Government Primary School Ndongo all in Buea Sub-Division. Any school chosen for this study was in respect to its knowledge on children with reading difficulties, its population and accessibility.

The validation of the research instruments was based on content validity which focused on the extent to which the content of the instruments corresponded to the content of the theoretical concept they were designed to measure. Content validity was assured by using the content validity index (CVI) whereby the instrument for data collection was checked by experts in the field of dyslexia and curriculum development.

\subsection{Methods of Data Processing and Analysis}

The quantitative data was analysed by using a pre-designed EpiData Version 3.1 (EpiData Association, Odense Denmark, 2008) database which has in-built consistency and validation checks was used to enter the data. Further consistency, data range and validation checks were also performed in SPSS version 21.0 (IBM Inc., 2012) to identify invalid codes. Data were made essentially of categorical variables and they were analyzed using frequency and proportions and Multiple Response Analysis to aggregate responses within conceptual components. Reliability test was performed to assess the internal consistency of responses using Cronbach Alpha reliability analysis. Chi-Square test was used to compare proportions for significant difference. 
Table2. Reliability analysis for the pre-testing of the instrument

\begin{tabular}{|l|l|l|l|}
\hline Conceptual components & Cronbach's Alpha & $\mathbf{N}_{\text {cases }}$ & $\mathbf{N}_{\text {item }}$ \\
\hline Material quantity taught per day & 0.529 & 10 & 8 \\
\hline Classroom management and lesson delivery & 0.489 & 10 & 8 \\
\hline IVM & 0.595 & 10 & 16 \\
\hline
\end{tabular}

The internal consistency assumption was not violated for any of the conceptual components with all Alpha values equal or greater than 0.5 .

Composite variables were generated to aggregate scores within conceptual components and their effect on material quantity taught per day and classroom management. Accommodation as the dependent variables was measured using Spearman's Rho correlation test because all the variables violated the normality assumption at the 0.05 level (Kolmogorov-Smirnov tests for normality: $\mathrm{P}<0.05)$. In fact, these tests of normality verified the null hypothesis making sure that the real distribution of the data did not depart significantly from the theoretical assumed normal distribution.

\section{FINDINGS}

\subsection{Effect of Material Quantity Taught Per Day on the Effectiveness of Learners with Dyslexia}

Table3. Teacher characterisation of the quantity of material taught per day on the effectiveness of learners with Dyslexia by background indicators

\begin{tabular}{|c|c|c|c|c|c|}
\hline \multirow[t]{2}{*}{ Indicators } & \multirow[t]{2}{*}{ Categories } & \multicolumn{2}{|c|}{$\begin{array}{l}\text { Characterization of the Quantity of } \\
\text { Material Taught per Day }\end{array}$} & \multirow[t]{2}{*}{$\mathbf{N}_{\text {responses }}$} & \multirow[t]{2}{*}{ Chi-square } \\
\hline & & Agree & Disagree & & \\
\hline \multirow[t]{2}{*}{ Gender } & Male & $53.9 \%(69)$ & $46.1 \%(59)$ & 128 & \multirow{2}{*}{$\begin{array}{l}\chi^{2}=0.45 \\
p=0.504\end{array}$} \\
\hline & Female & $50.5 \%(198)$ & $49.5 \%(194)$ & 392 & \\
\hline \multirow[t]{3}{*}{ Class } & Nursery to class two & $55.4 \%(133)$ & $44.6 \%(107)$ & 240 & \multirow{3}{*}{$\begin{array}{l}\chi 2=5.55 \\
\mathrm{p}=0.048\end{array}$} \\
\hline & Class 3 to 4 & $51.8 \%(87)$ & $48.2 \%(81)$ & 168 & \\
\hline & Class 5 to 6 & $42.0 \%(47)$ & $58.0 \%(65)$ & 112 & \\
\hline
\end{tabular}

Teachers teaching from the nursery section to class two with a proportion of 55.4\% (133) were the most comfortable with the quantity of material taught per day, followed by class 3 and 4 teachers with proportion of $51.8 \%$ (87). Those teaching classes 5 to 6 were the least comfortable with a proportion of $42.0 \%$ (47) and the difference was statistically significant $(\mathrm{P}<0.05)$ therefore implying that teachers ability to cope with quantity of material taught per day was significantly dependent on the class taught. The male and the female statistically had almost the same level of satisfaction with proportions of $53.9 \%$ and $50.5 \%$ respectively $(\mathrm{P}>0.05)$.

Table4. Teacher's characterization of the quantity of material taught per day on the effectiveness of learners with dyslexia

\begin{tabular}{|l|l|l|l|}
\hline Statements & Agree & Disagree & N \\
\hline I usually teach strictly following the prescribed scheme of work & $87.7 \%(57)$ & $12.3 \%(8)$ & 65 \\
\hline $\begin{array}{l}\text { I always cover my content for the day despite the differences in the } \\
\text { reading abilities of my learners }\end{array}$ & $32.3 \%(21)$ & $67.7 \%(44)$ & 65 \\
\hline $\begin{array}{l}\text { Some children always go home without completing the work in } \\
\text { class }\end{array}$ & $78.5 \%(51)$ & $21.5 \%(14)$ & 65 \\
\hline $\begin{array}{l}\text { I find it difficult to reduce some of the material content for some } \\
\text { slow learners in class }\end{array}$ & $58.5 \%(38)$ & $41.5 \%(27)$ & 65 \\
\hline Average pass in my class will drop if I teach few items & $44.6 \%(29)$ & $55.4 \%(36)$ & 65 \\
\hline $\begin{array}{l}\text { When I use pictures and other materials in teaching, children end up } \\
\text { forgetting the lessons }\end{array}$ & $3.1 \%(2)$ & $96.9 \%(63)$ & 65 \\
\hline $\begin{array}{l}\text { Children are more careful when they have limited task under } \\
\text { limited time }\end{array}$ & $64.6 \%(42)$ & $35.4 \%(23)$ & 65 \\
\hline $\begin{array}{l}\text { When I reduce the number of items the rate at which children ask or } \\
\text { answer questions drops }\end{array}$ & $41.5 \%(27)$ & $58.5 \%(38)$ & 65 \\
\hline Multiple response set (MRS) & $51.3 \%(267)$ & $48.7 \%(253)$ & 520 \\
\hline
\end{tabular}

In aggregate, almost half of the teachers giving a proportion of $51.3 \%$ (167) were comfortable with the quantity of material they teach per day. They acknowledged that they usually teach strictly following the prescribed scheme of work 87.7\%(57), that some children always go home without completing the work assigned to them in class $78.5 \%(51)$, that children are more careful when they 
have limited task under limited time 64.6\%(42), they find it difficult to reduce some of the material content for some slow learners in class $58.5 \%$ (38), when they reduce the number of items the rate at which children ask or answer questions drops $41.5 \%(27)$. The teachers agreed that they always cover the content for the day despite the differences in the reading abilities of the learners $32.3 \%$ (21).

Table5. Relationship between material quantity taught per day and the effectiveness of learners with dyslexia

\begin{tabular}{|l|l|l|}
\hline Spearman's Rho & Effectiveness of learners with dyslexia \\
\hline \multirow{2}{*}{$\begin{array}{l}\text { Material quantity taught per } \\
\text { day }\end{array}$} & $\mathrm{R}$ & $0.360^{* *}$ \\
\cline { 2 - 3 } & P-value & 0.003 \\
\cline { 2 - 3 } & $\mathrm{N}$ & 65 \\
\hline
\end{tabular}

**. Correlation is significant at the 0.01 level (2-tailed).

There was statistically enough evidence that material quantity significantly and positively impact the test performance by children with dyslexia. $(\mathrm{r}=0.360 ; \mathrm{P}=0.003)$.

\subsection{Classroom Management and Content Delivery for Learners with Dyslexia}

Table6. Teacher perception of adjustment in classroom management on content delivery by background indicators

\begin{tabular}{|l|l|l|l|l|l|}
\hline Indicators & Categories & \multicolumn{2}{|l|}{$\begin{array}{l}\text { Teacher's Perception of Adjustment in } \\
\text { Classroom Management }\end{array}$} & $\mathbf{N}_{\text {responses }}$ & Chi-square \\
\hline & & Agree & Disagree & & \\
\hline \multirow{2}{*}{ Gender } & Male & $24.2 \%(31)$ & $75.8 \%(97)$ & 128 & $\chi 2=2.70$ \\
& Female & $31.9 \%(125)$ & $68.1 \%(267)$ & 392 & $\mathrm{p}=0.100$ \\
\hline \multirow{2}{*}{ Class } & Nursery to class two & $35.8 \%(86)$ & $64.2 \%(154)$ & 240 & $\chi 2=7.29$ \\
\cline { 2 - 5 } & Class 3 to 4 & $24.4 \%(41)$ & $75.6 \%(127)$ & 168 & $\mathrm{p}=0.026$ \\
\cline { 2 - 5 } & Class 5 to 6 & $25.9 \%(29)$ & $74.1 \%(83)$ & 83 & \\
\hline
\end{tabular}

Teachers teaching nursery to class two were the most comfortable with adjustment in classroom management having a proportion of $35.8 \%$ (86), followed by Class 5 and 6 teachers with a proportion of $25.9 \%$ (29), then those teaching class 3 to 4 had the least satisfaction with a proportion of $24.4 \%$ (41) and this difference was statistically significant $(\mathrm{P}<0.05)$ therefore implying that teachers' willingness to adjust classroom management roles depended on the class taught. The female were more satisfied than the male with proportions of $31.9 \%$ (125) and $24.2 \%$ (31) respectively though this difference was statistically significant.

Table7. Teacher's Perception of Adjustment in Classroom Management on Content Delivery

\begin{tabular}{|l|l|l|l|}
\hline Statements & Agree & Disagree & N \\
\hline $\begin{array}{l}\text { My class is smart and I don't waste time on one person or some } \\
\text { children because work must be finished }\end{array}$ & $12.3 \%(8)$ & $87.7 \%(57)$ & 65 \\
\hline $\begin{array}{l}\text { Children who are slow should be sent to another room for remedial } \\
\text { teaching. }\end{array}$ & $49.2 \%(32)$ & $50.8 \%(33)$ & 65 \\
\hline $\begin{array}{l}\text { I find it difficult to prepare extra material to just a few learners or a } \\
\text { learner in class. }\end{array}$ & $40.0 \%(26)$ & $60.0 \%(39)$ & 65 \\
\hline $\begin{array}{l}\text { Giving other children different material out of the prescribed content } \\
\text { disrupts my class session }\end{array}$ & $49.2 \%(32)$ & $50.8 \%(33)$ & 65 \\
\hline $\begin{array}{l}\text { Giving different activities for different groups of learners in one class } \\
\text { creates indiscipline in the class }\end{array}$ & $41.5 \%(27)$ & $58.5 \%(38)$ & 65 \\
\hline $\begin{array}{l}\text { Labelling children "dull”, "last cocoa" etc. is ok because it } \\
\text { challenges them to work harder }\end{array}$ & $9.2 \%(6)$ & $90.8 \%(59)$ & 65 \\
\hline $\begin{array}{l}\text { I have my routine programme that is well understood by children and } \\
\text { changing it will distort their understanding }\end{array}$ & $29.2 \%(19)$ & $70.8 \%(46)$ & 65 \\
\hline Class rules are not needed in today's classroom & $9.2 \%(6)$ & $90.8 \%(59)$ & 65 \\
\hline Multiple response set (MRS) & $30.0 \%(156)$ & $70.0 \%(364)$ & 520 \\
\hline
\end{tabular}

In aggregate, less than half of teachers with a proportion of $30.0 \%$ (156) were satisfied with classroom management. In detail, $49.2 \%$ (32) perceived that giving other children different material out of the prescribed content disrupts the class session that children who are slow should be sent to another room for remedial teaching $49.2 \%$ (32). They believed that giving different activities for different groups of learners in one class creates indiscipline in the class $41.5 \%(27), 40.0 \%$ (26) find it difficult to prepare extra material for just a few learners in class, $29.2 \%$ (19) have their routine programme that 
is well understood by children and changing it will distort their understanding, $12.3 \%$ (8) perceived that their class is smart and they don't waste time on one person or some children because work must be finished, meanwhile 9.2\% (6) perceived that class rules are not needed in today's classroom.

Table8. Relationship between classroom management content delivery for children with dyslexia

\begin{tabular}{|l|l|l|l|}
\hline & & & Lesson delivery content for children with dyslexia \\
\hline \multirow{3}{*}{ Spearman's rho } & $\begin{array}{l}\text { Classroom } \\
\text { management }\end{array}$ & $\mathrm{R}$ & $0.573^{* *}$ \\
\cline { 3 - 4 } & & $\mathrm{P}$-value & 0.000 \\
\cline { 3 - 4 } & $\mathrm{N}$ & 65 \\
\hline
\end{tabular}

**. Correlation is significant at the 0.01 level (2-tailed).

There was statistically enough evidence that classroom management significantly and positively impact the test performance of children with dyslexia. $(\mathrm{r}=0.573 ; \mathrm{P}=0.000)$.

\section{DISCUSSIONS}

Despite the fact that teachers faced a lot of difficulties in teaching children with dyslexia in regular classrooms as revealed by the findings of this study, there was enough statistical evidence that material quantity taught per day significantly and positively influenced the effectiveness of learners with dyslexia. Material quantity taught per day calls for content adaptation. Majority of the teachers as revealed also by the findings of the study adjusted their curriculum with the intention in mind to improve on learners' performances and also to meet their learning needs. This finding ties with that of Prater (2007) who found that decreasing the amount of material to be read by the learner can increase comprehension. Moreover, according to Ebeling, Deschenes and Sprague (1994), material quantity taught per day which is simply adapting the number of items that the learner is expected to learn or number of activities the student will complete prior to assessment have been found useful in teaching learners with dyslexia. Although more than half the number of teachers faced difficulties in reducing the material content for some slow learners in class, at the same time, a majority of them believed that the use of pictures and other materials in teaching can help children understanding the lessons better.

According to Prater (2007) materials can be adapted by using voice- recorded materials; DVDs; simplified versions of the classroom text; changing the modality of text input, usually "reading it aloud" or on audio file; allowing a peer to read a text to a learner and decreasing the amount or density of content (such adaptations include selecting another text with similar content by using easier vocabulary, highlighting key concepts, omitting unnecessary or distracting parts of context, or writing abridged versions of text). Furthermore, Smith (2007) and Miller (2009) looks at content adaptation as adapting what is taught as well as adapting how learners are given access to what they need to learn. Adapting what is taught may include a completely different curriculum (substituting curriculum) or an adaptation in curricular goals (alternative goals). Content changes may also involve the amount or difficulty of level of the work to be achieved. One strategy for dealing with content accommodation is to select the core concepts each learner must master.

In the light of the fact that classroom management is an indispensable aspect in teaching, findings in this study also reveals that a significant and positive relationship exist between classroom management and content delivery for learners with dyslexia. This implies that the better the management of classrooms by teachers, the better the content delivery for learners with dyslexia. According to Eggen and Kauchak (2007), effective classroom management builds self-esteem in the learner. It is a creative and imaginative way in daily lessons delivery that motivates and provides a safe and comfortable learning environment for all learners. Emmer and Stough (2001) and Jones (2005) in Eggen and Kauchak (2007) mention that developing learner responsibility requires a cognitive approach to management, an approach that emphasizes the creation of an orderly classroom through the development of learner understanding.

Brown (2004), Emmer and Stough (2001) in Eggen and Kauchak (2007) states that creating a positive classroom environment is an essential component of a productive learning environment. When the climate is positive, both the teacher and the learner demonstrate mutual respect and courtesy, and everyone feels safe to express thoughts and opinions without fear of embarrassment or ridicule. An essential element of a positive classroom environment is a caring teacher who communicates, respect and show concern for others (Certo, Cauley and Chafen 2002 and Davis 2003 in Eggen and Kauchak, 2007). 


\section{RECOMMENDATIONS}

Based on the presented findings, several issues would need to be addressed in order to enhance the implementation of curriculum adaptation in regular schools for children with dyslexia. The following recommendations are among the issues that can be addressed to enhance the implementation of curriculum adaptation.

Educational policies should be reviewed to take full account of individual differences and situations.

$>$ There should be cooperation among teachers, children and parents. Cooperation helps the teaching and learning process in schools to run smoothly

$>$ Teaching and learning materials which might be helpful for teachers during adaptation of curriculum should be provided in order to help learners with dyslexia.

Teachers should know that it is right to be different and accept their learners the way they are while taking into consideration that they strengths and weaknesses.

$>$ The curriculum of Cameroon's Basic Education Sector should be revised and made more flexible so that teachers have room to use different teaching styles to achieve the same objectives.

$>$ It is recommended that curriculum designers and educators of special education should be jointly responsible for training teachers on curriculum adaptation.

\section{CONCLUding ReMARKS}

The findings from this study show that, to a large extent curriculum adaptation will give learners with dyslexia access to regular schools. In order for the regular schools in Buea Sub-Division to cater for all their learners with dyslexia, it is of utmost importance to implement curriculum adaptations for this category of learners while they are still in lower grades so that they could improve and not end up in resource centres or special schools. A majority of the teachers have not been adapting their curriculum for lack of knowledge of inclusive practices coupled with the lack of materials and facilities. However, other factors also compounded these challenges. But these can be surmounted if all stakeholders particularly the teachers of regular schools are involved in decision making.

\section{REFERENCES}

American Psychiatric Association. (2000). American Psychiatric Association Diagnostic and Statistical Manual of Mental Disorders, 4th Edition.

Barrow, R. (1984). Giving teaching back to teachers: A critical introduction to curriculum theory. London, ON: The Althouse Press

Barrow, R. (1984). Giving teaching back to teachers: A critical introduction to curriculum theory. London, ON: The Althouse Press

Bergmann. J., \& Wimmer, H. (2008). A dual-route perspective on poor reading in a regular orthography: Evidence from phonological and orthographic lexical decisions. Cognitive Neuropsychology, 25, 653-676.

Coltheart M, Rastle K., Perry C., Langdon R., \& Ziegler, J. (2001). DRC: a dual route cascaded model of visual word recognition and reading aloud, Psychol Rev. 200;108(1):204-56.

Donald, D., Lazarus, S. \& Lowalna, P. (2002). Educational Psychology in social context (2 ${ }^{\text {nd }}$ edition). Oxford University Press.

Ebeling, D., Deschenes, C., \& Sprague, J.(1994). Adapting curriculum \& instruction in inclusive classrooms: A teacher's desk reference. Bloomington.

Eggen, P. \& Kauchak, D. (2007). Educational psychology: Windows on Classrooms (7th ed.). Upper Saddle River: Merrill Prentice Hall.

Elbro, C., \& Pallesen, B. R. (2002). The quality of phonological representations: A causal link? In L. Verhoeven, C. Elbro, \& P. Reitsma (Eds.), Precursors of functional literacy (Vol. 11, pp. 1732). Amsterdam: John Benjamins.

Emmer, E., \& Stough, L. (2001). Classroom management: A critical part of educational psychology, with implications for teacher education. Educational Psychologist , 36 , 103-112. 
Fawcett A. J., \& Nicolson R. I. (2004). The dyslexia screening test-Junior. London: Harcourt Assessment.

Irby, B.J., Brown, G., Lara-Alecio, and Jackson, S. (eds.). (2013). The handbook of educational theories. Charlotte, NC: Information Age Publishing.

Johnsen \& M. D. Skjørten (Eds.). (2001). Education - Special Needs Education: An Introduction (pp.173 - 186). Oslo: Unipub.

Lieberman, D. (1985). Research on children and microcomputers: A review of utilization and effects studies. In Chen, M. and Paisley, W. (eds.), Children and Microcomputers. Beverly Hills, Calif.: Sage Publications 59-83.

Liberman, I. Y., Shankweiler, D. P., Orlando, C., Harris, K., \& Bell-Berti, F. (1971). Letter confusions and reversals of sequence in the beginning reader: Implications for Orton's theory of developmental dyslexia. Cortex, 7, 127-142.

Mansor, A. N., Eng, W. K., Rasul, M. S., Hamzah, M. I. M., \& Hamid, A. H. A. (2012). Effective classroom management. International Education Studies, 5(5), 35-42.

Miller, S.P. (2009). Validated practices for teaching students with diverse Needs and abilities (2nd ed.). Upper Saddle River: Pearson.

Mzizi, N. A. (2014). Curriculum adaptations for learners with learning impairments in the foundation phase in Thabo Mofutsanyane District Free State. Central University of Technology, Free State.

Orton, S. T. (1925). "'Word-Blindness' in School Children;" Archives of Neurology and Psychiatry, 1581-615.

Prater, M.A. (2007). Teaching strategies for students with mild to moderate disabilities. Boston: Allyn and Bacon

Richardson. V. \& Fallona. C. (2001). Classroom management as method and manner. Curriculum studies, vol.33, no.6, 705

Reid, G. (2009) Dyslexia: A Practitioners Handbook (4th Edition) Wiley.

Stanovich, K. E. (1990) Concepts in developmental theories of reading skill: Cognitive resources, automaticity, and modularity. Developmental Review 10:72-100.

UNESCO (2004). "Curriculum in Early Childhood Education and Care", UNESCO Policy Brief on Early Childhood, No. 26, UNESCO, Paris.

UNESCO, (1990). World Conference on Education for All in Jomtien, Thailand.

WHO. (2010). International classification of functioning, disability and health (ICF).

\section{AUTHOR's BIOGRAPHY}

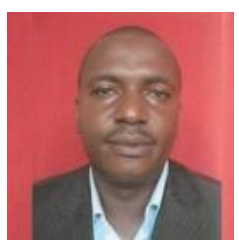

Patrick Fonyuy Shey, is a Senior Lecturer of Special Education and particularly Learning Disabilities and Inclusive Education. He has particular interest on the Inclusion of persons with disabilities in Regular Schools. He has participated in several research projects in Inclusive Education within Cameroon and beyond. He is involved in post graduate research supervision and other research endeavors and has published widely on Inclusive Education, Social Skills with over 15 Peer Reviewed Papers. His current research explores the role teachers and other stakeholders play in the effective implementation of Inclusive Education in Ordinary Schools, and he is leading a team of researchers on a study on the Level of Satisfaction of Beneficiaries of the Inclusive Education Pilot Project in the South West Region of Cameroon, sponsored by Sightsavers Cameroon Country Office. Since 2012 he has been a Consultant/Trainer to Sightsavers and other Organizations on issues of Inclusivity. 